\title{
Meio ambiente, capitalismo e desenvolvimento sustentável: a arquitetura de um matrimônio duvidoso
}

François M. P. Gavard ${ }^{1}$

\begin{abstract}
RESUMO: A revolução no pensamento e na relação do homem com o meio ambiente advinda do Iluminismo desencadeou durante a Modernidade um processo de desenvolvimento econômico e tecnológico que ao alcançar o século XX demonstrou-se problemático trazendo a perspectiva da finitude e do limite de volta às consciências. Movimentos sociais se organizaram reivindicando a conservação do meio ambiente e a ciência e o capitalismo foram apontados com responsáveis pela destruição do ambiente natural. $\mathrm{O}$ debate em torno da problemática ambiental era pautado pelo impasse entre as posições antagônicas de "ambientalistas" e "desenvolvimentistas". Na busca da superação deste impasse foram articulados os conceitos de "Ecodesenvolvimento" e posteriormente o de Desenvolvimento Sustentável. O primeiro foi rejeitado devido ao seu conteúdo excessivamente político e de partir de premissas que contrariavam os interesses da economia mundial. O segundo ganhou proeminência no discurso ambiental e teve ampla aceitação nos mais diversos setores devido ao seu caráter conciliador que afirmava a possibilidade de se alcançar um tipo de desenvolvimento capaz de contemplar os aspectos sociais, econômicos e ecológicos. Ainda que elaborado de maneira vaga e alvo de suspeita de mera estratégia discursiva.
\end{abstract}

Palavres -chave: Meio ambiente. Ecodesenvolvimento. Desenvolvimento Sustentável.

\section{ENVIRONMENT, CAPITALISM AND SUSTAINABLE DEVELOPMENT: THE ARCHITECTURE OF A DOUBTFUL MARRIAGE}

ABSTRACT: The revolution in thought and in man's relationship with the environment arising during the Enlightenment triggered during the Modren Age a process of economic and technological development that when reaching twentieth century was demonstrated problematic, bringing the perspective of the finitude and the limit back to consciousness. Social movements have been articulated demanding the preservation of the environment and science and capitalism have been appointed as responsibles for the destruction of the environment. The discussion around the environmental issue was guided by the impasse between the antagonistic positions of "environmentalists" and "developmentalists". In search of overcoming this impasse were articulated the concept of "Ecodevelopment", later on, Sustainable Development. The first one was rejected because of its excessive political content

\footnotetext{
${ }^{1}$ Bacharel em Ciências Sociais (UFSM), mestrando em Ciências Sociais do PPGCS - UFSM, e-mail: françois_gavard@yahoo.com.br.
} 


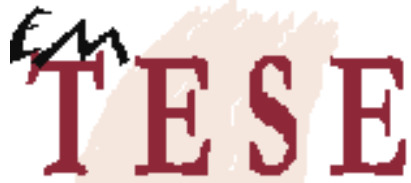

\section{Revista Eletrônica dos Pós-Graduandos em Sociologia Política da UFSC}

Vol. 6 - n. 3 janeiro-julho/2009

ISSN 1806-5023

and from premises that contradicted the interests of the world economy. The second one gained prominence in environmental discourse and had wide acceptance in several sectors because of its conciliator character that affirmed the possibility of achieving a kind of development able to contemplate the social, economic and ecological aspects. Despite drafted in a vague way and the target of suspicion of mere discursive strategy.

Keywords: Environment. Ecodevelopment. Sustainable Development.

\section{1- Introdução:}

Apesar de recente, a percepção da degradação dos recursos naturais como um problema de primeira linha agenda política internacional - veio a adquirir este status apenas a partir da década de setenta - já possui um histórico bastante rico e conturbado. Poucos problemas da atualidade ganharam, em um lapso tão curto de tempo, tanta visibilidade, mobilizaram uma gama tão larga de atores sociais, suscitaram debates tão acalorados e formaram opiniões tão apaixonadas quanto tendenciosas. Dada a transversalidade do problema, é normal que a sua dinâmica histórica seja resultante de uma batalha disputada por diversos e poderosos interesses que lançarão mão de diferentes estratégias de ação institucionais, políticas e discursivas - visando, frequentemente, acima da efetiva resolução da crise ambiental a busca da realização de seus próprios objetivos, ainda que conflitantes com o objetivo maior da preservação e da busca pela sustentabilidade.

Este artigo irá abordar, em linhas gerais, as grandes transformações pelas quais passou a percepção da crise ambiental, da natureza do debate entorno da temática e dos termos em que foram propostas as suas alternativas de resolução, destacando-se como ponto de inflexão deste processo o surgimento do conceito de Desenvolvimento Sustentável. Conceito que, a partir do final da década de oitenta, realizou a façanha de conseguir conciliar pontos de vista antagônicos sob sua égide sendo evocado pelos atores envolvidos na discussão dos problemas ambientais (e mesmo sendo adotado por atores em contextos diversos) como uma forma de deus ex machina para a resolução destes. Veremos que este processo se deu, em alguma medida, por um deslocamento de foco no sentido de canalizar o debate para zonas menos 


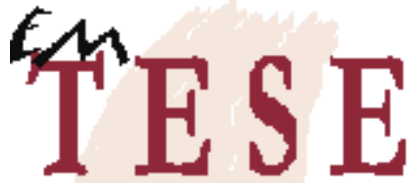

Revista Eletrônica dos Pós-Graduandos em Sociologia Política da UFSC

Vol. 6 - n. 3 janeiro-julho/2009

ISSN 1806-5023

conflituosas onde houvesse a possibilidade de se chegar a um entendimento em relação à questão que se adequasse aos interesses da ordem econômica e política mundiais. Mesmo que o preço pago para assumir um tom conciliador tenha sido o da imprecisão conceitual, dando margem a críticas e desconfiança por parte de alguns.

\section{2 - Crise ambiental e crise da modernidade:}

A ação humana na busca de garantir as condições de sua reprodução enquanto espécie é modificadora do seu entorno físico, pelo menos a partir do momento em que se organiza em sociedade e realiza a transição cultural do nomadismo para o sedentarismo. Este estágio, conhecido como Revolução Neolítica marca uma etapa fundamental na longa trajetória do esforço da espécie humana em dominar a natureza de modo a garantir sua subsistência. Cumprida esta etapa necessária para o crescimento demográfico - e evocando Durkheim, conseqüente incremento em complexidade e diferenciação sociais - civilizações conhecerão apogeu e queda, tendo sempre que encontrar soluções para o problema de extrair desta dimensão material da realidade os meios que lhe permitam realizar o desejo quimérico de perpetuação na superfície desse planeta solitário à deriva no éter. Assim, a história da presença do homem sobre a Terra, como afirma Moscovici (2007) é também a história da ação humana sobre a natureza

Aceitando-se que a relação do homem com a natureza é fundamentalmente instrumental e que não pode deixar de sê-lo em considerável medida, esta relação nem sempre se deu sobre as mesmas bases. Durante a maior parte da História as sociedades encararam a natureza mais ou menos nos termos do enigma da esfinge: decifra-me ou te devoro. Terremotos, vulcões, furacões, secas, enchentes, tempestades, pragas, feras, vírus e bactérias em princípio conjurados pelo poder das divindades passaram, num processo lento e progressivo, a ser conjurados também pelo poder do conhecimento. Assim foi até chegarmos aos umbrais de uma época única na história humana em que se operaram algumas das maiores 


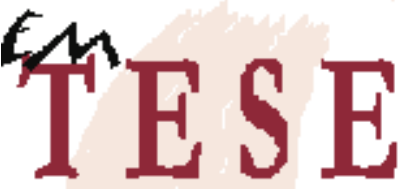

Revista Eletrônica dos Pós-Graduandos em Sociologia Política da UFSC

Vol. 6 - n. 3 janeiro-julho/2009

ISSN 1806-5023

transformações experimentadas por esta espécie no campo do saber, da técnica e do seu próprio estatuto ontológico. A partir do início da era moderna aquele processo lento e progressivo rumo a um avanço tecnológico conhece um salto qualitativo e temporal em que a relação com o ambiente físico passa a se dar numa dimensão até então desconhecida.

Junto com os triunfos notórios da técnica e da razão moderna, atrelada vem a crença de que a humanidade atingira um estágio em que o mundo natural não mais interpunha obstáculos aos desígnios dos homens. Esta concepção libertária de homem e sociedade inerentes ao projeto da modernidade apresenta estreita afinidade com uma forma particular de desenvolvimento econômico, aliás, a proeminência da orientação para a acumulação de capital é um dos elementos fundamentais para a compreensão das instituições modernas. Giddens (1996) assevera que o avanço da civilização moderna tem como signo distintivo a tentativa da imposição do controle humano sobre os meio ambientes de ação, entre eles o natural. Esta orientação para o controle, por sua vez, liga-se fortemente à ênfase num tipo de desenvolvimento econômico contínuo. Esta afinidade entre controle humano sobre o mundo e determinado tipo de ordem econômica típica da modernidade será ressaltada por Weber (1992) ao identificar um processo progressivo e inexorável de avanço de uma racionalidade instrumental - orientada a fins - que tenderá a organizar as relações sociais e que encontrará na burocracia e na esfera econômica o seu paroxismo.

A própria ciência econômica, definida até hoje coma a ciência da escassez, inicialmente orientada pela perspectiva de um ambiente de meios escassos para satisfazer um universo de necessidades infinitas, com o advento da indústria capitalista - impulsionada pelas possibilidades de uma nova matriz energética baseada nos combustíveis fósseis presenciará a adoção por parte das sociedades modernas de uma lógica de compulsão para o crescimento. Um crescimento contínuo ${ }^{2}$, necessário à manutenção do modo de produção

\footnotetext{
${ }^{2}$ Aron (1999) comentando o clássico estudo de Max Weber sobre o espírito do capitalismo ressalta um dos aspectos distintivos do capitalismo burguês moderno em relação às demais formas históricas de busca pelo lucro. Para Weber o apetite ilimitado pelos ganhos não é o que caracteriza o capitalismo moderno, mas sim o fato deste
} 


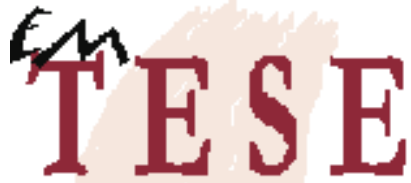

Revista Eletrônica dos Pós-Graduandos em Sociologia Política da UFSC

Vol. 6 - n. 3 janeiro-julho/2009

ISSN 1806-5023

capitalista, onde os limites naturais não são divisados num horizonte próximo. De acordo com Goldblat (1996):

Com a chegada do capitalismo e da tecnologia industrial, esta dinâmica mostrar-seia capaz de gerar abundância material, na qual se poderia construir uma forma avançada de organização social. As sociedades modernas não foram realmente coagidas por limites naturais (GOLDBLAT, 1996, p.22).

No entanto, os efeitos deste novo modo de produção não tardaram em fazer sentir seus efeitos seja sobre o tecido social, seja sobre o meio ambiente. A intensidade das transformações ocorridas na sociedade derivadas do advento do capitalismo industrial, foi acompanhada por um intenso processo de depredação de recursos naturais, criando uma dinâmica de desenvolvimento em que a perseguição do lucro vinha associada à absorção pelas sociedades e o meio ambiente dos efeitos negativos do processo.

Para a reflexão deste quadro Lemkov (2002) indica como uma das mais originais contribuições para a teoria social, antes da publicação das obras de Giddens e Beck, os trabalhos de Schnaiberg e Gorz que abordaram a dialética entre desenvolvimento capitalista e crise energética/ecológica no quadro de uma teoria marxista renovada. O primeiro destaca a desorganização dos ecossistemas ocasionada por um modelo de crescimento orientado à produção de excedentes gerando o que chama de um "capital de energia intensiva" (LEMKOV, 2002 p.127) que, por sua vez, redunda na disseminação de riscos sociais como ameaças para a saúde das pessoas e para a manutenção da produção sociocultural das populações (desemprego, diminuição da renda, etc.). Tais ameaças, para Schnaiberg, poderiam causar a erosão da base material da sociedade capitalista e talvez propiciarem transformações sociopolíticas.

André Gorz (Apud Lemkov 2002) deu destaque a associação entre acumulação capitalista e crise ecológica. Ao problematizar a capacidade do sistema capitalista em superar os efeitos nocivos por ele mesmo gerados sobre o ambiente, acrescenta a já conhecida noção

ser animado pelo desejo da acumulação contínua. Desta atitude de busca de acumulação contínua decorre a necessidade de um amento de produção indefinido.

Em Tese, Vol. 6, n. 3, janeiro/julho 2009, p. 25-42 


\section{筑ESE}

Revista Eletrônica dos Pós-Graduandos em Sociologia Política da UFSC

Vol. 6 - n. 3 janeiro-julho/2009

ISSN 1806-5023

marxista de crise de acumulação capitalista uma crise ecológica dela decorrente. Conforme Gorz, existe uma contradição no sistema capitalista em que os custos ambientais crescem mais rapidamente que os recursos econômicos disponíveis para sanar os problemas ecológicos gerados pela atividade econômica e pelo aumento constante e acelerado do consumo. $\mathrm{O}$ autor argumenta que tal contradição somente poderá ser superada por uma reforma que extrapole os limites da esfera econômica indicando como imprescindível resituar e redefinir os conceitos culturais dominantes de riqueza, crescimento econômico, consumo e trabalho.

Levando-se em conta a centralidade da economia capitalista e o modo de produção industrial para a compreensão e caracterização das instituições da modernidade, como tem sido demonstrado desde os primórdios da sociologia por autores como Weber e Durkheim até a sociologia contemporânea por autores como Giddens e Habermas, por exemplo, facilmente pode-se partir da crítica destes elementos para uma contestação de caráter mais amplo identificando a crise ambiental como um sintoma de uma crise mais profunda do próprio projeto da modernidade. Sob esta ótica as transformações no meio ambiente que estão sendo presenciadas pelas sociedades atuais seriam, em última instância, reflexo de uma crise paradigmática.

Neste contexto, os movimentos ambientais surgidos nos anos sessenta podem ser interpretados como sintomas de um processo, indicado por Giddens (1995), amplo de destradicionalização e perda de valores decorrentes de um estágio tardio alcançado pela modernidade e a crise ecológica, para a qual estes reivindicam a atenção da sociedade e do Estado, constitui a expressão material dos limites da modernidade.

Este quadro indica a existência uma antinomia fundamental, ainda que apresentada de diferentes modos, que perpassa todo o debate sobre a problemática ambiental desde os primórdios de seu avatar contemporâneo - década de 60 - até meados da década de 80 (isto se não levarmos em consideração as críticas dos ambientalistas mais radicais que, nos dias atuais, fundamentam suas reivindicações nesta antinomia). Trata-se do conflito entre preservação de recursos naturais e meio ambiente e capitalismo industrial. Ainda que o 


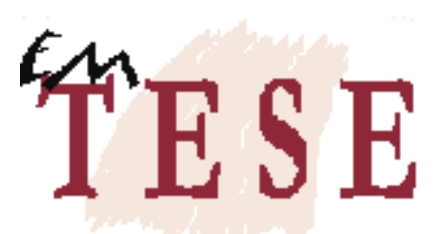

\section{Revista Eletrônica dos Pós-Graduandos em Sociologia Política da UFSC \\ Vol. 6 - n. 3 janeiro-julho/2009 \\ ISSN 1806-5023}

diagnóstico sobre as origens da crise ambiental tenha suscitado discussões a respeito de sobre quem deveria recair a culpa, capitalismo ou industrialismo (GOLDBLAT, 1996) ${ }^{3}$, os debates sobre a questão ambiental estiveram por bastante tempo fortemente marcados pelo antagonismo entre um modelo de desenvolvimento econômico e seus impactos sobre o ambiente natural.

Se a natureza dos problemas ambientais era percebida nestes termos, a solução plausível não pode ser outra que uma de cunho reformista. Apenas uma reforma completa e profunda não somente da ciência e da economia, mas sim, do pensamento e de visão de mundo poderia evitar os cenários apocalípticos evocados. Tal concepção que opõe frontal e definitivamente preservação ambiental e modo de produção capitalista ${ }^{4}$ estava implícita nos debates de finais dos anos sessenta sobre a crise ambiental. Colocada dessa forma a questão, interesses de ambientalistas e capitalistas apresentam-se inconciliáveis e o ambiente de disputa política sobre o tema tendia ao impasse.

\section{3 - Do impasse ao consenso:}

Um momento emblemático deste impasse criado entre desenvolvimento econômico capitalista e preservação ambiental foi a publicação do estudo intitulado The Limits to Growth em 1972 - que daria a tônica dos debates da Conferência da ONU sobre Meio Ambiente Humano realizada em Estocolmo neste mesmo ano e em grande parte dos debates durante toda a década. Este estudo coordenado por Dennis Meadows e encomendado pelo Clube de

\footnotetext{
${ }^{3}$ Este autor aponta que diferentes atores envolvidos com a questão ambiental fazem diferentes juízos em relação a atribuição de culpa. Os partidos verdes europeus tendem a afirmar que o industrialismo é o principal responsável pela degradação ambiental tanto nas economias capitalistas quanto nas socialistas. Contrariamente, os marxistas buscam as origens estruturais dos problemas ambientais na dinâmica do modo de produção capitalista. Já os economistas que se ocupam da questão ambiental, sejam os de orientação liberal ou socialdemocrata, têm insistido na afirmação que o problema não pode ser atribuído a uma característica intrínseca a forma de operarem os mercados e a posse privada do capital e sim a defeitos de orientação e regulação do capitalismo.

${ }^{4}$ Visto enquanto um desdobramento necessário do projeto da modernidade.
}

Em Tese, Vol. 6, n. 3, janeiro/julho 2009, p. 25-42 


\section{筑ESE}

Revista Eletrônica dos Pós-Graduandos em Sociologia Política da UFSC

Vol. 6 - n. 3 janeiro-julho/2009

ISSN 1806-5023

Roma trazia à baila uma perspectiva neomalthusiana para a questão, onde a finitude dos recursos era reintroduzida ${ }^{5}$ na discussão econômica e cenários de catástrofe eram projetados em um horizonte não muito distante, caso as variáveis de crescimento industrial, população e recursos naturais não se alterassem ${ }^{6}$. Na maneira que aparecia em The Limits to Growth a introdução da idéia de finitude no modo de produção traduzia-se, necessariamente, em catástrofe (Nobre, 2002).

A problemática encarada sob esta perspectiva induzia a uma busca de solução que passaria, inelutavelmente, na redução do uso dos recursos naturais e, corolário disto, na colocação de um freio nos índices de crescimento das economias nacionais, aprecia neste momento a polêmica proposta do "crescimento zero". Obviamente que tal visão sombria para o futuro do modelo capitalista de desenvolvimento haveria de suscitar reações. De um lado os economistas do mainstream rapidamente se esforçaram em exorcizar o fantasma malthusiano seja alegando a possibilidade de substituição da matéria prima por outros fatores de produção como o trabalho e o capital reprodutível ou, numa linha argumentativa diversa, destacando alguns vícios de origem nas conclusões daquele estudo, como no caso da falsidade da premissa de que a estrutura econômica, política e social permaneceria a mesma no longo prazo (Nobre, 2002).

Outra reação despertada pela proposta do "crescimento zero" veio da parte dos países do Terceiro Mundo que viam com desconfiança a idéia de que o desenvolvimento econômico seria o responsável pela degradação do ambiente e consideravam a alternativa de estagnação como uma estratégia imperialista da parte dos países do Primeiro Mundo. Para estes países era inegociável uma estratégia de superação da crise ambiental que se desse nestes termos, de forma que, doravante, os interesses dos países deste bloco deveriam, de alguma forma, serem contemplados ou ao menos levados em consideração para que pudesse ser estabelecida uma

\footnotetext{
${ }^{5}$ Uma visão abandonada desde os fisiocratas em meados do século XIX.

6 Previsões que iam, inclusive, além do pessimismo original de Malthus, na medida que apontavam para um colapso do sistema não apontado por este autor.
}

Em Tese, Vol. 6, n. 3, janeiro/julho 2009, p. 25-42 


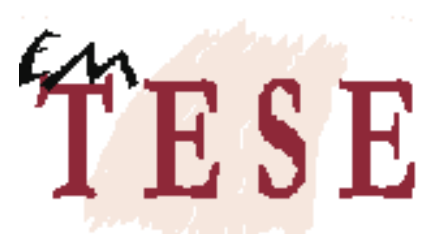

\section{Revista Eletrônica dos Pós-Graduandos em Sociologia Política da UFSC \\ Vol. 6 - n. 3 janeiro-julho/2009 \\ ISSN 1806-5023}

agenda internacional para resolução da problemática ambiental. Nobre (2002) resume os termos em que se dava a discussão e a posição dos países do Terceiro Mundo:

Neste contexto, a posição dos países do Terceiro Mundo, embora diversificada, era unânime na rejeição da imposição de limitações ao crescimento econômico. Do ponto de vista diplomático, não havia meio de se chegar a algum acordo internacional de caráter global que fosse consistente. Simplesmente por porque a posição mesma do problema impedia qualquer acordo. E a equação era bastante simples: Se há contradição entre desenvolvimento capitalista (no sentido de crescimento econômico) e meio ambiente, não há por que defender o capitalismo. Se não há contradição entre os dois termos, não há por que impor restrições à utilização dos recursos naturais (NOBRE, 2002 p.37).

É no sentido de tentar superar estas divergências que é proposto pelo PNUMA em 1975 o conceito de "ecodesenvolvimento" que punha em destaque um tipo de desenvolvimento calcado na dimensão regional e local e ao uso adequado dos recursos naturais. Ignacy Sachs será o grande defensor e propagador deste conceito, vindo a estender o conteúdo originalmente proposto ao mesmo. Sachs (2007) designa sob este termo, ao mesmo tempo, um novo estilo de desenvolvimento e um novo enfoque (participativo) de planejamento e gestão, orientado por um conjunto interdependente de postulados éticos, à saber: atendimento das necessidades humanas fundamentais (materiais e intangíveis), promoção da auto-confiança das populações envolvidas e o cultivo da prudência ecológica. Neste quadro, variáveis como a redução do consumo supérfluo e do desperdício por parte da minoria rica e a cobertura universal das necessidades fundamentais da maioria pobre e socialmente excluída assumiam papel proeminente. Em suma, conjunto de postulados ligado a um estilo de desenvolvimento que contemplava especialmente os interesses de ambientalistas e das populações dos países pobres.

Como se pode observar, este conceito trazia em seu âmago questões extremamente delicadas e potencialmente problemáticas para sua aceitação e implementação no cenário mundial - especialmente em relação às economias centrais - como mudanças nos hábitos de consumo e processo produtivo. Além do seu conteúdo político que estava centrado na idéia de emancipação das populações pobres. Tais noções comprometiam de sobremaneira sua transposição ao campo da ação concreta e também não eram capazes de criar um ambiente 


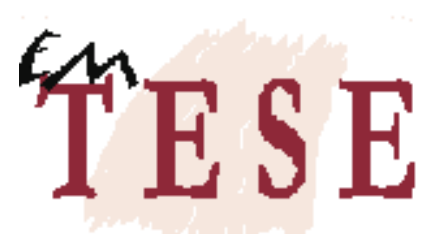

\section{Revista Eletrônica dos Pós-Graduandos em Sociologia Política da UFSC \\ Vol. 6 - n. 3 janeiro-julho/2009 \\ ISSN 1806-5023}

favorável ao diálogo com os representantes dos interesses capitalistas. O resultado disto foi o abandono do conceito de "ecodesenvolvimento" alguns anos mais tarde. Leff aponta alguns motivos do fracasso do conceito de "ecodesenvolvimento":

O potencial do Ecodesenvolvimento foi se dissolvendo nas suas próprias estratégias teórico-práticas. As suas propostas esbarraram na dificuldade de se flexibilizar as instituições e os instrumentos de planificação para se romper com a lógica economicista (LEFF, 2006 p.136).

Contudo, o problema fundamental da relação entre crescimento econômico e preservação de recursos naturais permanecia atual e não resolvida. Como em qualquer outra questão social, este debate não se deu em termos inalteráveis ao longo do tempo. Na medida que estava submetido à dinâmica histórica, fatores conjunturais viriam a alterá-lo, ou, ao menos, mudar o peso atribuído aos argumentos articulados pelos interesses em litígio.

A entrada da década de 80 viria a estabelecer uma nova base para a discussão da problemática ambiental. A visão pessimista dos anos 70 da relação entre crescimento/preservação que opunha inconciliavelmente "desenvolvimentistas" e "preservacionistas" foi substituída por uma visão otimista em relação ao crescimento econômico no quadro das economias de mercado ocidentais. As economias americana e inglesa, capitaneadas pelos princípios neoliberais, começaram a apresentar resultados positivos e a saírem de um período de estagnação econômica decorrente de algumas décadas de welfare state. A chamada "Era Reagan"7 proporcionou um recrudescimento na confiança da capacidade do mercado - desbaratado dos liames da intervenção estatal - e do crescimento econômico $^{8}$ em solucionar uma ampla gama de problemas sociais, entre eles os que concernem o meio-ambiente. Conforme Woodgate (2002) esta fé no crescimento e no mercado teve como conseqüência a afirmação de que a "anomalia" da escassez poderia ser solucionada facilmente liberando o mercado das restrições governamentais. Nesta perspectiva

\footnotetext{
7 Sem esquecer da ex-primeira ministra britânica Margareth Tatcher, talvez a chefe-de-estado mais fervorosa na defesa das idéias de Von Hayek.

${ }^{8}$ Esta é a teoria do Trickle Down, pela qual bastaria garantir o crescimento macroeconômico que seu benefícios escorreriam abaixo pela pirâmide social irrigando todo o tecido societário (Sachs, 2008).
}

Em Tese, Vol. 6, n. 3, janeiro/julho 2009, p. 25-42 
Revista Eletrônica dos Pós-Graduandos em Sociologia Política da UFSC

Vol. 6 - n. 3 janeiro-julho/2009

ISSN 1806-5023

a economia de mercado seria o instrumento regulador por excelência na resolução dos problemas ambientais ${ }^{9}$ (Leff, 2000).

No caudal destas idéias é proposto o conceito de Desenvolvimento Sustentável (DS) no início da década de oitenta. Conforme o que foi exposto, a conjuntura do período não se mostrava favorável à receptividade de um tipo de argumentação centrada numa crítica ambientalista da economia e numa solução orientada unicamente pela parcimônia no uso dos recursos e nos hábitos de consumo. Fazia-se necessário que a problemática ambiental fosse re-elaborada ${ }^{10}$ em termos negociáveis entre os interesses divergentes envolvidos, num esforço em se encontrar uma alternativa entre posições que acentuavam a dicotomia entre o que Sachs (2007 p.203) qualifica do "estritamente econômico e o incondicionalmente ecológico".

Não se sabe ao certo qual foi a primeira vez em que este termo foi usado, mas pode-se indicar que foi na ocasião da publicação do World Conservation Strategy (WCS) pela International Union for Conservation of Nature and Natural Resources (IUCN) em 1980 que o conceito adquire proeminência. Este documento veiculava, como idéia central, a pretensão de se buscar um tipo de desenvolvimento ${ }^{11}$ compatível com a conservação dos recursos naturais, sendo desta forma, sustentável. Ao direcionar os holofotes, em primeiro lugar, para

\footnotetext{
${ }^{9}$ Note-se que este ponto de vista está em flagrante antagonismo com a visão dos anos 70 em que justamente a economia capitalista é a responsável causal da degradação dos recursos. Nesta nova perspectiva o próprio veneno servira como antídoto.

${ }^{10}$ Vale frisar, neste ponto, a visão de Hannigan (2000) sobre a problemática ambiental. Este autor aborda o tema sob a perspectiva construcionista que procura compreender como os problemas ambientais são formulados, contestados e legitimados socialmente. O caminho entre a percepção de uma ameaça ao meio ambiente, a sensibilização da opinião pública e a posterior produção de regulamentação legislativa se faz por um longo processo em que diversos atores disputam a prevalência de seus interesses. Neste processo, numerosos fatores internos e externos ao próprio mérito da questão, intervêm a ponto do resultado final, não raro, comportar um significativo grau de casualidade. Para este autor o próprio conceito de meio ambiente é de natureza fluída, culturalmente baseado e socialmente contestado. Os termos em que será dado o debate passarão por uma fase de conceituação e legitimação e, tendo êxito, serão canalizados para as estruturas de poder econômico e político.

${ }^{11}$ Importante perceber uma mudança sutil em relação aos termos empregados. Se a opinião nos anos 70 era do conflito entre crescimento econômico e preservação ambiental, a partir dos anos 80, na busca de se superar o impasse, emprega-se preferencialmente o termo desenvolvimento, que trazia um conteúdo mais vasto, contemplando aspectos que vão além da esfera estritamente econômica, relacionado-se à satisfação de necessidades intangíveis tais como qualidade de vida, , justiça social, e, obviamente, preservação de recursos naturais.
}

Em Tese, Vol. 6, n. 3, janeiro/julho 2009, p. 25-42 


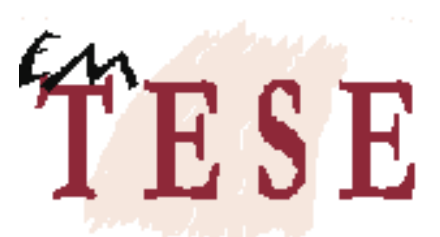

\title{
Revista Eletrônica dos Pós-Graduandos em Sociologia Política da UFSC \\ Vol. 6 - n. 3 janeiro-julho/2009 \\ ISSN 1806-5023
}

questão da preservação de recursos naturais, se estabelece uma significativa distinção em relação aos pressupostos assumidos pelo abandonado conceito de "ecodesenvolvimento". A atenção foi parcialmente desviada dos aspectos mais problemáticos que emperravam a negociação, notadamente os relativos à ordem institucional, econômica e política ${ }^{12}$, a mudança nos padrões de consumo e aumento da população. De acordo com Lima (2003), uma das particularidades na noção de DS foi o esvaziamento de seu conteúdo político, especialmente em relação às cocepções de Ignacy Sachs onde era central a idéia de uma forma de desenvolvimento com potencial emancipador para os países pobres. Nobre avalia esta guinada na ênfase posta nos termos relativos ao problema da seguinte forma:

\begin{abstract}
O que era a primeira vista um recuo incompreensível tornou-se uma grande jogada estratégica, se pensarmos que abriu caminho para acordos de futura importância. (...) ao deixar em suspenso as questões políticas e institucionais, o WCS afastou exatamente o que emperrava qualquer avanço negociado. (...) veio para o primeiro plano a necessidade de preservar, conservar, de maneira que, ao retornarem as velhas questões (crescimento econômico, desigualdades sociais, instituições políticas internacionais, etc.), elas viriam reorganizadas segundo este ponto de vista, abrindo caminho para o "desenvolvimento sustentável" tal como seria definido depois pelo Relatório Brundtland (NOBRE, 2002 p.38)
\end{abstract}

O resultado desta mudança na maneira de se apresentar o problema mostrou-se positivo enquanto estratégia para introduzir o conceito de Desenvolvimento Sustentável na arena da política internacional. A prova disto foi a mudança de atitude dos países em desenvolvimento em relação à problemática ambiental, manifesta na sessão especial do PNUMA $^{13}$ realizada em Nairobi em 1982. Ao invés da rejeição enfática da saída pelo "crescimento zero" recomendada em Limits to Growth e, mais ainda, em lugar de um ponto de vista que afirmava a incompatibilidade entre modo de produção capitalista e preservação ambiental, agora, tornara-se possível alcançar um acordo com aqueles países em torno de um conceito de desenvolvimento que incluísse as questões ambientais sem prejudicar seus interesses econômicos - e nem os interesses do "grande capital" (Nobre, 2002). Nesta ocasião

\footnotetext{
${ }^{12}$ Ressaltando-se, no entanto que a noção de desenvolvimento sustentável proposta nesta publicação não omitia a dimensão social, na verdade já trazia a noção atual da conjugação dos aspectos do tripé econômico, social e ecologico (Peixoto;Ribeiro e Xavier, 2008).

${ }_{13}^{13}$ Programa das Nações Unidas Para o Meio Ambiente.
}

Em Tese, Vol. 6, n. 3, janeiro/julho 2009, p. 25-42 


\section{筑ESE}

Revista Eletrônica dos Pós-Graduandos em Sociologia Política da UFSC

Vol. 6 - n. 3 janeiro-julho/2009

ISSN 1806-5023

é proposta a formação da Comissão Mundial sobre Meio Ambiente e Desenvolvimento (WCED) - conhecida como comissão Brundtland ${ }^{14}$ - que, em 1987, irá dar ao conceito de Desenvolvimento Sustentável sua definição mais célebre: aquele que atende às necessidades do presente sem comprometer a capacidade de as gerações futuras também atenderem as suas.

Nesta formulação, conceito de DS assevera a possibilidade de a economia mundial manter seus níveis de crescimento sem comprometer a disponibilidade de recursos naturais no longo prazo e o instrumento indicado como capaz de proporcionar este quadro é avanço científico/tecnológico. Neste contexto, o fantasma malthusiano da escassez será conjurado pelo recurso da ciência ${ }^{15}$, sendo capaz, desta forma, de relegar ao segundo plano a consígnia ambientalista de parcimônia e de prudência em relação ao uso de recursos naturais. Refletindo uma particularidade na percepção da problemática ambiental típica deste momento, a de que a consciência em relação aos problemas ambientais na sociedade cresce na mesma proporção que a crença de que a ciência e a tecnologia possuem os instrumentos necessários para reverter os problemas por ela gerados. Desta forma o estágio tardio alcançado pelo processo de industrialização carrega esta ambiguidade e discurso da sustentabilidade o reflete (Demajorovic, 2003).

Cabe destacar que, a despeito das críticas mais incisivas ao conceito de DS omitirem, a formulação do conceito presente no Relatório Brundtland é de natureza multidimensional, contemplando as dimensões da prudência ecológica e eficiência econômica e justiça social ${ }^{16}$. Este relatório também enfatiza a importância da cooperação internacional e do multilateralismo no enfrentamento dos desafios de final de século, ressaltando ainda, que os problemas do meio ambiente e do desenvolvimento sustentável se encontram diretamente relacionados com os problemas da pobreza (Lima, 1997). De forma que o conteúdo atribuído ao conceito neste documento, amplia o escopo e sofistica o debate entorno da questão

\footnotetext{
${ }^{14}$ Que levava o nome da então primeira ministra norueguesa Gro Harlem Brundtland, presidente da comissão.

${ }^{15}$ Como, de fato, já acontecera ao longo do século XIX, onde a adoção progressiva de novas técnicas agrícolas e a utilização de combustíveis fósseis na indústria fizeram parecer afastada - ou protelada - a possibilidade de escassez.

${ }^{16}$ Ainda que estas dimensões sejam abordadas de maneira vaga segundo Wolfgang Sachs (2002).

Em Tese, Vol. 6, n. 3, janeiro/julho 2009, p. 25-42 


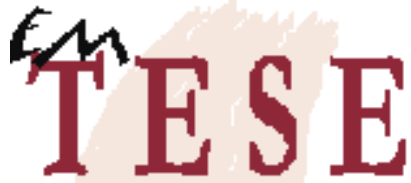

Revista Eletrônica dos Pós-Graduandos em Sociologia Política da UFSC

Vol. 6 - n. 3 janeiro-julho/2009

ISSN 1806-5023

ambiental, sem, contudo, perder seu tom conciliador. Neste sentido, o conceito ali proposto é inovador e constitui um avanço politico e diplomático em relação às formulações anteriores.

O conceito irá se consagrar definitivamente por ocasião da Conferência das Nações Unidas para o Meio Ambiente e Desenvolvimento (CNUMAD) em 1992, mais conhecida como ECO-92 (ou Rio-92), realizada no Rio de Janeiro. Neste momento ${ }^{17}$ ele demonstrou ser uma estratégia vitoriosa para a institucionalização da problemática ambiental no âmbito da agenda política internacional, na esfera governamental, agências de auxílio, empresas e políticas públicas (Nobre, 2002).

O conceito de DS deu prova de persistência e crescente aceitação ao chegar, hodiernamente, a impor-se como recurso retórico indispensável nos discursos dos mais diferentes atores sociais ligados de alguma forma à problemática ambiental, ainda que localizados em campos opostos e sendo empregue mesmo em contextos que, historicamente, não estiveram diretamente envolvidos na construção da problemática ambiental, como no campo da educação, por exemplo (Lima, 2003). E muito disto se deu em função de um alargamento de significado progressivo a que foi submetido o conceito desde sua proposição vindo a incorporar noções como governança, ampliação dos espaços democráticos, cidadania e inclusão social.

\section{4- Considerações finais:}

Marcos Nobre afirma que o conceito de Desenvolvimento Sustentável surgiu "não só como noção fadada a produzir consenso, mas também como um enigma a ser criticado por sua vaguidão, imprecisão e caráter contraditório" (Nobre, 2002 p.25). Do ponto de vista lógico, quando se entende que o conceito de DS afirma a possibilidade de se manter um nível de crescimento contínuo sem comprometer a manutenção de estoques finitos de recursos

\footnotetext{
${ }^{17}$ Quando, nas palavras de Sachs: “(...) o adjetivo sustentável se tornou imperativo na retórica mundial.” (Sachs, 2007, p. 285).
} 


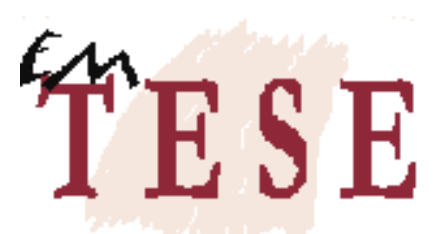

\section{Revista Eletrônica dos Pós-Graduandos em Sociologia Política da UFSC \\ Vol. 6 - n. 3 janeiro-julho/2009 \\ ISSN 1806-5023}

naturais, este se aproxima de um sofisma e a crítica pode, com razão, acusá-lo de encerrar em seus termos uma contradição semântica. Outra acusação freqüente é a de que, apesar de declarar a possibilidade do conúbio entre desenvolvimento e meio ambiente, não indica de maneira convincente qual seria o mecanismo - afora uma aposta na tecnologia - para transpor o conceito ao nível da ação. Ao simplesmente asseverar uma situação sem oferecer os elementos que a tornariam factível, o emprego do conceito se assemelha a uma profissão de fé mais do que uma tentativa positiva de resolução da problemática ambiental ${ }^{18}$.

Outra acusação de que o conceito é vítima é a de se tratar de uma estratégia para submeter a problemática ambiental aos interesses da globalização, indicando o mercado e a economia de orientação neoliberal como capazes de incorporar a dimensão ecológica sem a necessidade de intervenção estatal. Neste sentido o discurso da sustentabilidade seria uma forma de conferir legitimidade à economia de mercado (Leff, 2006) e evitar que a questão ambiental possa dar ensejo a uma maior intervenção estatal na economia ${ }^{19}$.

A força de agregar uma pluralidade de interesses sob sua égide, o conceito teve de formulá-los de maneira vaga, evitando formulações restritivas que pudessem vir a prejudicar seu caráter conciliador. Decorre disto a acusação freqüente de conceito polissêmico e obscuro, permitindo diferentes leituras e atribuições de significado, que podem variar de interpretações vinculadas a um tipo de desenvolvimento progressista associando à preservação ambiental, justiça social e participação política, ou, a um tipo de desenvolvimento conservador que simplesmente alia a variável ambiental à noção de crescimento econômico (Lima, 1997).

\footnotetext{
${ }^{18}$ Alguns vão ainda mais longe. Nobre (2002) é particularmente cáustico na crítica ao conceito. O considera produto de uma grande operação diplomática, ideológica e social para superar o debate ambiental nos termos em que estava proposto nos anos 70, sem, no entanto, resolver o impasse que estava colocado. Basicamente afirma que a superação da contradição entre termos - meio ambiente e crescimento econômico - foi superada simplesmente pela adoção do artifício retórico de afirmar-se através de um conceito deliberadamente vago que estes termos não são contraditórios.

19 Neste aspecto, autores como Sachs e Leff enfatizam a incapacidade do mercado em lidar com questões multidimensionais e na perspectiva do longo prazo como o caso da conservação do meio ambiente. Para estes autores o caminho em busca da sustentabilidade não pode evitar uma redefinição do papel do Estado enquanto agente planificador e regulador.
}

Em Tese, Vol. 6, n. 3, janeiro/julho 2009, p. 25-42 


\section{筑ESE}

Revista Eletrônica dos Pós-Graduandos em Sociologia Política da UFSC

Vol. 6 - n. 3 janeiro-julho/2009

ISSN 1806-5023

Não obstante às críticas a ele endereçadas, é forçoso constatar, assumindo-se uma posição mais realista do que crítica, que o conceito de DS foi o responsável pela façanha de desatar o nó górdio que atravancava o debate, desde finais da década de sessenta, entre "ambientalistas" e "desenvolvimentistas". E isto não é pouca coisa. Abriu um campo de debate onde os interesses em jogo pudessem se confrontar de forma menos entrincheirada que em períodos anteriores, apontando para a possibilidade de se alcançar uma solução negociada. Este conceito teve o mérito de disseminar a temática ambiental nos canais do poder e do capital, fazendo com que migrasse - ainda que não com o mesmo conteúdo - do terreno das pregações ambientalistas exclusivamente, para as instâncias definidoras de políticas públicas e da atividade econômica. Ilustrando grosseiramente a sua contribuição para o percurso histórico da problemática ambiental, o conceito de DS foi o responsável por fazer com que preservação da natureza passasse de uma reivindicação de hippies dos anos sessenta para uma preocupação de primeira hora dos dirigentes das grandes corporações do século XXI.

Porém, o quadro não se apresenta de todo alvissareiro. Paira a suspeita de que o conceito venha sendo utilizado como peça retórica visando conferir legitimidade a atividades potencial ou efetivamente danosas ao meio ambiente, especialmente pelo segmento empresarial. A adesão retórica ao conceito serviria, nestas situações, para conferir uma imagem "ecologicamente correta" às empresas, visando agregar valor aos seus produtos ou propiciando vantagem competitiva simplesmente. Além disto, na medida que o segmento passe a difundir amplamente este tipo de mensagem, o mesmo pode estar sendo utilizado para criar um ambiente desfavorável a uma ampliação, eventualmente necessária, da legislação ambiental e de aumento no rigor em sua fiscalização.

Admite-se que o conceito de DS se preste a este tipo de uso devido a duas particularidades a ele inerentes: seu conteúdo vago e a sua ampla aceitação na sociedade. Para que este possa afastar esta suspeita de artimanha discursiva e possa efetivamente se converter em uma ferramenta para se alcançar uma "situação triplamente ganhadora" (Sachs, 2007 p.268), ou seja, um tipo de desenvolvimento em que as dimensões social, econômica e 


\section{䇰ESE}

Revista Eletrônica dos Pós-Graduandos em Sociologia Política da UFSC

Vol. 6 - n. 3 janeiro-julho/2009

ISSN 1806-5023

ecológica sejam contempladas, se faz necessário um esforço no sentido de uma atribuição de conteúdo mais clara e precisa, que ofereça efetivamente os meios para que se alcance a meta aludida bem como aponte mecanismos de mensuração para práticas sustentáveis.

\section{5- Bibliografia:}

DEMAJOROVIC, Jacques. Sociedade de risco e responsabilidade socioambiental: perspectivas para a educação corporativa. São Paulo: Editora Senac, 2003.

GANDY, Mattew. Pós-modernismo e ambientalismo: discursos complementares ou contraditórios? In: REDCLIFT, Michael; WOODGATE, Grahan. Sociologia del medio ambiente: una perspectiva internacional. Madrid: Mcgraw-Hill/Interamericana de Espana, 2002

GIDDENS, Anthony. Para Além da Esquerda e da Direita. São Paulo: Editora UNESP, 1995.

GOLDBLAT, David. Teoria Social e Ambiente. Lisboa: Instituto Piaget, 1996.

HANNIGAN, J. Sociologia Ambiental. A formação de uma perspectiva social. Lisboa: Instituto Piaget, 2000.

LEFF, Enrique. Racionalidade Ambiental. A reapropriação social da natureza. Rio de Janeiro: Civilização Brasileira, 2006.

LIMA, Gustavo F. da Costa. O debate da sustentabilidade na sociedade insustentável. Política e Trabalho, João Pessoa, v. 13, p. 201-222, set. 1997.

. O discurso da sustentabilidade e sua implicações para a educação.

Ambiente \& Sociedade, v. 6, n. 2, jul./dez., 2003.

Em Tese, Vol. 6, n. 3, janeiro/julho 2009, p. 25-42 


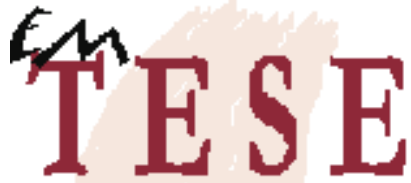

Revista Eletrônica dos Pós-Graduandos em Sociologia Política da UFSC

Vol. 6 - n. 3 janeiro-julho/2009

ISSN 1806-5023

MOSCOVICI, Serge. Natureza: para pensar a ecologia. Rio de Janeiro: Mauad, 2007.

NOBRE, Marcos. Desenvolvimanto sustentável: origens e significado atual. In: NOBRE, Marcos; AMAZONAS, Maurício de C. (Orgs.). Desenvolvimento sustentável: a institucionalização de um conceito. Brasília: Ed. IBAMA, 2002.

REDCLIFT, Michael; WOODGATE, Grahan. Sustentabilidade e construção social.In: Sociologia del medio ambiernte: una perspectiva internacional. Madrid: McgrawHill/Interamericana de Espana, 2002

SACHS, Ignacy. Rumo à Ecossocioeconomia. São Paulo: Cortez, 2007.

. Desenvolvimento includente, sustentável e sustentado. Rio de Janeiro:

Garamond, 2008.

SACHS, Wolfgang. Desenvolvimento sustentável. In: REDCLIFT, Michael; WOODGATE, Grahan. Sociologia del medio ambiernte: una perspectiva internacional. Madrid: McgrawHill/Interamericana de Espana, 2002

SMITH, Mark J. Manual de Ecologismo: Rumo à cidadania ecológica. Lisboa: Instituto Piaget, Colecção Perspectivas Ecológicas, 2001. 